\title{
Bone mineralization, geometry and strength in pigs growing from 56 to 115 day of life as affected by body fatness
}

KEY WORDS: dual energy X-ray absorptiometry, bone mineralization, bone geometry, bone strength, body fatness, piglets

Received: $\quad 25$ March 2016

Revised: $\quad 20$ June 2016

Accepted: 25 November 2016
${ }^{1}$ Corresponding author: e-mail: g.skiba@ifzz.pl

\begin{abstract}
The aim of this study was to investigate a morphometry (bone mass), densitometry (mineral content, mineral density measured using dual energy X-ray absorptiometry (DXA) method), geometry (cortical wall thickness, cross sectional area, cortical index) and bone strength in weaned female piglets growing from 56 to 115 day of life and differed in body fatness understood as fat : lean mass ratio established using DXA. Correlations between measured properties and body fatness were also considered. Sixteen 56-day old crossbreed piglets were allotted into two experimental groups (8 animals in each): thin $-T$ (fat : lean mass ratio $<0.12$ ) and fat $-F$ (fat : lean mass ratio $>0.12$ ), based on fat : lean mass ratio in the body. Both groups of pigs were fed the same diet ad libitum (13.5 MJ $\cdot \mathrm{kg}^{-1}$ metabolizable energy, $10.5 \mathrm{~g}$ of digestible lysine per $\mathrm{kg})$. At 115 day of life the T animals had heavier bones $(P<0.01)$, higher bone mineral content $(P<0.01)$, higher bone mineral density $(P<0.05)$, higher cortical wall thickness $(P<0.01)$ and cross sectional area $(P<0.01)$ in comparison to $\mathrm{F}$ pigs. Bone strength and cortical index did not differ between groups. Body fatness was negatively correlated with: bone weight $(r=-0.55$, $P=0.001)$, bone mineral content $(r=-0.52, P=0.001)$, bone mineral density $(r=-0.27, P=0.029)$, cortical wall thickness $(r=-0.38, P=0.002)$ and cross sectional area $(r=-0.57, P<0.001)$. Correlations with bone strength and cortical index (relative proportion of cortical bone to total periosteal breadth at midshaft) were insignificant.
\end{abstract}

\section{Introduction}

Body composition is presented by densitometry as a sum of fat mass, non-bone lean mass (muscle mass) and bone mineral content (Rothney et al., 2009). Content of the first two components, especially fat, can influence bone size, mineral content and density in adolescents (Janicka et al., 2007; Farr et al., 2010; Cole et al., 2012; Mosca et al., 2014) and adults (Reid et al., 1992; Kirchengast et al., 2001; Hsu et al., 2006; Dytfeld et al., 2011). The results of recent works (Wetzsteon et al., 2008; Aguirre et al., 2014) indicated also that the proportion between fat : lean mass in the body has an important meaning. However, results of these studies, carried out using both dual energy X-ray absorptiometry (DXA), computed tomography (CT) and peripheral quantitative computed tomography (pQCT) method, are divergent. Additionally, some authors (Reid et al., 1992) pointed out that relationship between fat and bone understood as whole body mineral density is influenced by sex and is significant in females but much weaker in males. Mosca et al. (2014) reported higher negative relationship between body fat and whole body bone mineral content in males, whereas in females such relationship was observed in femur and spine. 
There are still relatively few studies and data regarding the relation between body fatness expressed as fat : lean mass ratio, bone geometry and bone strength based on direct measurements in humans. Besides that these studies give only calculated indices, which could significantly vary from the actual measurements. The experiments conducted on animals are also spare. There are only few studies investigating bone properties of growing pigs using DXA method (Ryan et al., 2011a; Weremko et al., 2013; Skiba et al., 2015). Most studies concerning bone measurements in pigs were focused only on chemical composition, as well as mechanical, geometrical and densitometrical properties (Crenshaw et al., 1981; Shaw et al., 2006; Varley et al., 2011a,b). However, the relationship between pig body fatness understood as fat : lean mass ratio, and bone densitometry, bone geometry and bone strength was not investigated.

Thus, the aim of this study was to investigate bone morphometric properties (mass/weight), geometric characteristics (cortical wall thickness, cross sectional area, cortical index), parameters of mineralization (bone mineral content and bone mineral density) using DXA method, and bone strength in pigs growing from 56 to 115 day of life and differed in body fatness (fat : lean mass ratio). Moreover, correlations between measured bone properties and body fatness were also considered. It was assumed that body fatness would strongly influence the measured properties of bones in growing pigs.

\section{Material and methods}

All described procedures were approved by the III Local Ethics Commission on Animal Experimentation of the Warsaw University of Life Sciences SGGW (Poland).

Sixteen crossbreed female piglets were randomly selected from 8 litters ( 2 gilts per litter) at the day of weaning ( 28 day of life). Animals were kept in groups of 4 and subjected to acclimation (till 56 day of life). Then, each pig was weighed, scanned using DXA method (Norland XR- $800^{\mathrm{TM}}$ densitometer with software; Norland, a CooperSurgical Company, Fort Atkinson, WI, USA) to determine the fat : lean mass ratio in the body. Before scanning, animals were subjected to short-lasting sedation by injection of a mixture of ketamine hydrochloride $\left(2 \mathrm{mg} \cdot \mathrm{kg}^{-1}\right.$ body weight $(\mathrm{BW}))$ and xylazine $\left(0.2 \mathrm{mg} \cdot \mathrm{kg}^{-1} \mathrm{BW}\right)$, then placed in a ventral position with all limbs extended. The analysis was performed with the whole body application. To increase the accuracy of the measurement, the two scans on each pig were per- formed and then the average value was calculated. Scan revealed that average fat : lean mass ratio in the piglets body amounted $0.12( \pm 0.03)$, so piglets were allotted to two experimental groups ( 8 animals in each): thin $-\mathrm{T}$ (fat: lean mass ratio $<0.12$ ) and fat $-F$ (fat : lean mass ratio $>0.12$ ).

After scanning animals were transported to individual pens $\left(3.3 \mathrm{~m}^{2}\right)$ equipped with nipple drinker and were kept there on rubber mat till 115 day of life. Pigs from both groups were fed the same diet ad libitum (Table 1) given to stainless feeders. Content of digestible essential amino acids in the diets was calculated on the basis on tabular values according to Rademacher et al. (2001), and content of metabolizable energy - by tabular values of Beyer et al. (2003).

Table 1. Composition and nutritive value of feed

\begin{tabular}{|c|c|}
\hline Indices & Feed \\
\hline \multicolumn{2}{|l|}{ Ingredients, $\mathrm{g} \cdot \mathrm{kg}^{-1}$} \\
\hline barley & 264 \\
\hline wheat & 210 \\
\hline soyabean meal & 150 \\
\hline maize & 100 \\
\hline wheat starch & 95 \\
\hline rapeseed meal & 90 \\
\hline rapeseed oil & 45 \\
\hline mineral-vitamin-amino acid mixture ${ }^{1}$ & 30 \\
\hline calcium carbonate & 11 \\
\hline monocalcium phosphate & 5 \\
\hline \multicolumn{2}{|l|}{ Calculated chemical composition, $g$} \\
\hline dry matter & 899 \\
\hline organic matter & 870 \\
\hline crude protein & 160 \\
\hline crude fat & 64.7 \\
\hline ash & 28.7 \\
\hline crude fibre & 41.9 \\
\hline NDF & 138.1 \\
\hline ADF & 58.8 \\
\hline starch & 379.1 \\
\hline sugar & 38.9 \\
\hline \multicolumn{2}{|l|}{ Calculated nutritive value, $\mathrm{g} \cdot \mathrm{kg}^{-1}$} \\
\hline digestible protein & 130 \\
\hline lysine & 10.5 \\
\hline methionine & 3.6 \\
\hline cysteine & 2.2 \\
\hline threonine & 6.9 \\
\hline tryptophan & 2.0 \\
\hline $\mathrm{Ca}$ & 7.0 \\
\hline total $\mathrm{P}$ & 5.4 \\
\hline available $\mathrm{P}$ & 2.5 \\
\hline Calculated metabolizable energy, $\mathrm{MJ} \cdot \mathrm{kg}^{-1}$ & 13.5 \\
\hline
\end{tabular}

${ }^{1}$ mineral-vitamin-amino acids mixture consisted of: $\mathrm{g}$ : $\mathrm{Ca} 5.5, \mathrm{NaCl} 3$, P 1.15, lysine 4.07, methionine 1.35, threonine 1.97, tryptophan 0.15; mg: Fe 62.5, Zn 62.5, Mn 30.75, Cu 30, vit. D (cholecalciferol) 245, vit. $E 40$, vit. $K_{3} 2$, vit. $B_{1} 2$, vit. $B_{2} 2.5$, vit. $B_{6} 3.12$, vit. $B_{12} 20$; $\mu g$ : I 212, Se 205; IU: vit. A 2500 
Animals were kept in thermally neutral environment. Temperature was regulated by a Fancom ventilation system (Fancom BV, Panningen, the Netherlands) according to the age of pigs (from $24^{\circ} \mathrm{C}$ to $18{ }^{\circ} \mathrm{C}$ ).

At the end of the study (115 day of life) pigs were slaughtered (electrically stunned followed by exsanguination) and scanned using Norland XR- $800^{\mathrm{TM}}$ densitometer (Norland, a CooperSurgical Company, Fort Atkinson, WI, USA) in ventral position with all limbs extended. The analysis was performed with the whole body application to determine the fat : lean mass ratio in the body. Two scans were performed on each pig to increase the accuracy of the results and the average value was calculated. After scanning, the $3^{\text {rd }}$ metacarpal (3MC) and the $3^{\text {rd }}$ metatarsal $(3 \mathrm{MT})$ bones were collected from the left side of the carcass. Bones were cleaned of any remaining flesh with knives and scalpel blades, weighed, and their lenghts were measured. Bones were frozen $\left(-20{ }^{\circ} \mathrm{C}\right)$ for subsequent DXA scanning using 'Research' type scan. Specimens for scanning were thawed at room temperature (at $23{ }^{\circ} \mathrm{C}$ ) for $12 \mathrm{~h}$ prior to use. During scanning bones were positioned horizontally and scanned from the distal to the proximal end. The $3 \mathrm{MC}$ and $3 \mathrm{MT}$ were scanned in the dorsoplamar and dorsoplantar positions. All scans of the body and bones were obtained by standard procedure suggested by the manufacturer for scanning and analysis (Illuminatus DXA 4.4.1 scanner software ver. 2.3.1, Norland, a CooperSurgical Company, Fort Atkinson, WI, USA). A quality assurance test to verify the stability of the system calibration (control scan) was performed daily (accordingly to manufacturer instructions) to ensure the precision. Daily calibration procedure was performed using QC Phantom and QA Calibration standard (Norland, a CooperSurgical Company, Fort Atkinson, WI, USA). All of the scans were performed by the same operator. Bone mineralization was assessed as bone mineral content $(\mathrm{g})$ and bone mineral density $\left(\mathrm{g} / \mathrm{cm}^{2}\right)$.

After scanning three-point bending test using Texture Analyser - TAHdi (Stable Micro Systems LTD., Godalming, UK) with head speed of $1 \mathrm{kN}$, $10 \mathrm{~mm} \cdot \mathrm{min}^{-1}$ was applied to determine physical bone characteristics - maximum strength (the highest load before failure). Distance between the points of bone support equalled $40 \%$ of the bone length. After test, each bone was cut to measure its horizontal and vertical diameter (both external and internal). The measurements were performed using a calliper. Obtained values were used to calculate the geometric properties: cortical wall thickness, cross sectional area and cortical index according to the following formulas:

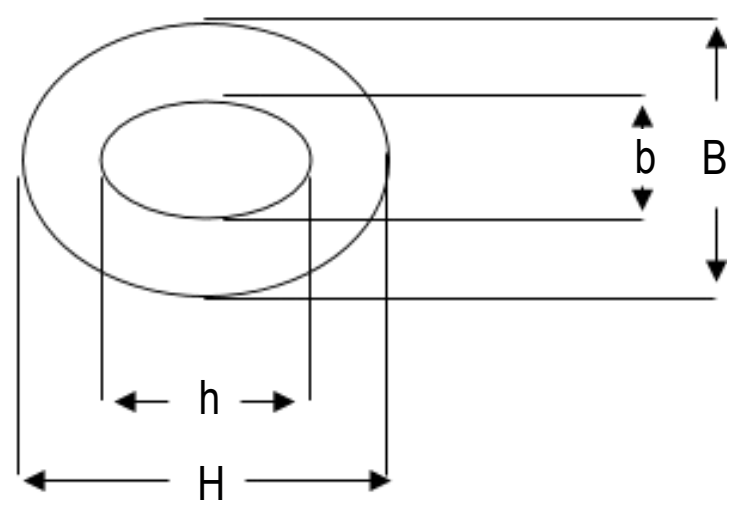

Figure 1. Measurements of external and internal diameters of bone cross-section

cortical wall thickness $=[(\mathrm{B}+\mathrm{H})-(\mathrm{b}+\mathrm{h})] / 4$ cross sectional area $=\Pi / 4 \times[(\mathrm{B} \times \mathrm{H})-(\mathrm{b} \times \mathrm{h})]$ cortical index $=[((\mathrm{H}-\mathrm{h}) / \mathrm{H})+((\mathrm{B}-\mathrm{b}) / \mathrm{B})]$

where: $\mathrm{B}$ - vertical external diameter, $\mathrm{H}$ - horizontal external diameter, $\mathrm{b}$ - vertical internal diameter, $\mathrm{h}$ horizontal internal diameter, $\Pi=3.14$. Scheme of the measurements is presented in Figure 1.

The results obtained during the whole pigs body scans were analysed using Student's t-test to compare both examined groups. The results obtained during bone scans were analysed using two-way analysis of variances (ANOVA) with group and bone type as experimental factors. Differences between treatments were tested using Student's t-test. $P$-value was considered statistically significant at $<0.05$. The relationship between body fat : lean mass vs bone weight, bone mineral content, bone mineral density, average cortical wall thickness, cross sectional area, cortical index and bone maximum strength were expressed using correlation coefficient based on results obtained from all animals at the end of the study. All statistical analyses were performed using Statgraphics Centurion Professional software ver. XVI (Statpoint Technologies, Inc., Warrenton, VA, USA).

\section{Results}

Initial fat : lean mass ratio in the body was lower $(P<0.01)$ in the T piglets. During whole period of the study animals from this group consumed daily less $(P<0.05)$ feed and had better $(P<0.01)$ feed efficiency (Table 2), however grew only slightly faster in comparison to $\mathrm{F}$ pigs (statistical difference observed for final body weights but not for average daily gains).

At the end of the study the T animals still had lower $(P<0.01)$ fat : lean mass ratio in the body, heavier bone mass $(P<0.01)$, higher bone mineral 
content $(P<0.01)$, bone mineral density $(P<0.05)$, cortical wall thickness $(P<0.01)$ and cross sectional area $(P<0.01)$ as compared to $\mathrm{F}$ pigs (Table 3$)$. Bone strength and cortical index did not differ between groups.

Table 2. Performance of pigs during whole period of growth ( 56 - 115 day of life)

\begin{tabular}{lcccc}
\hline \multirow{2}{*}{ Indices } & \multicolumn{2}{c}{ Group } & \multirow{2}{*}{ SEM } \\
\cline { 2 - 3 } & \multicolumn{2}{c}{$\mathrm{F}^{1}$} & $\mathrm{~T}^{2}$ & \\
\hline Initial body weight, $\mathrm{kg}$ & 18.5 & 18.1 & 0.41 \\
Final body weight, $\mathrm{kg}$ & $66.2^{\mathrm{B}}$ & $68.0^{\mathrm{A}}$ & 0.35 \\
Daily feed intake, $\mathrm{kg}$ & $2.12^{\mathrm{b}}$ & $1.81^{\mathrm{a}}$ & 0.08 \\
Average daily gain, $\mathrm{g}$ & 808 & 845 & 23.8 \\
Feed efficiency, $\mathrm{kg} \cdot \mathrm{kg}^{-1}$ gain & $2.62^{\mathrm{B}}$ & $2.15^{\mathrm{A}}$ & 0.06 \\
Initial fat : lean mass ratio in the body & $0.16^{\mathrm{B}}$ & $0.09^{\mathrm{A}}$ & 0.009 \\
Final fat : lean mass ratio in the body & $0.24^{\mathrm{B}}$ & $0.12^{\mathrm{A}}$ & 0.005 \\
\hline
\end{tabular}

${ }^{1} \mathrm{~F}$ - piglets with high fat : lean mass ratio in the body; ${ }^{2} \mathrm{~T}$ - piglets with low fat : lean mass ratio in the body; ${ }^{a b}$ and ${ }^{A B}-$ means with different superscripts within a row are significantly different at $P<0.05$ and $P<0.01$, respectively

Table 3. Bone characteristics at the end of the study (115 day of life)

\begin{tabular}{|c|c|c|c|c|}
\hline Group $^{1}$ & $\begin{array}{l}3^{\text {rd }} \text { bone of } \\
\text { metatarsal } \\
(3 \mathrm{MC})\end{array}$ & $\begin{array}{l}3^{\text {rd }} \text { bone of } \\
\text { metacarpal } \\
(3 \mathrm{MT})\end{array}$ & Mean & SEM \\
\hline \multicolumn{5}{|c|}{ Bone mass, $g$} \\
\hline $\mathrm{F}$ & 17.5 & 20.5 & $19.0^{\mathrm{A}}$ & \multirow[t]{3}{*}{0.273} \\
\hline $\mathrm{T}$ & 20.2 & 22.8 & $21.5^{\mathrm{B}}$ & \\
\hline Mean & $18.9^{A}$ & $21.7^{\mathrm{B}}$ & 20.3 & \\
\hline \multicolumn{5}{|c|}{ Bone mineral content, $\mathrm{g}$} \\
\hline $\mathrm{F}$ & 4.78 & 5.36 & $5.07^{\mathrm{A}}$ & \multirow[t]{3}{*}{0.070} \\
\hline $\mathrm{T}$ & 5.35 & 5.86 & $5.62^{\mathrm{B}}$ & \\
\hline Mean & $5.07^{\mathrm{A}}$ & $5.62^{\mathrm{B}}$ & 5.35 & \\
\hline \multicolumn{5}{|c|}{ Bone mineral density, $\mathrm{g} / \mathrm{cm}^{2}$} \\
\hline $\mathrm{F}$ & 0.395 & 0.405 & $0.400^{\mathrm{a}}$ & \multirow[t]{3}{*}{0.005} \\
\hline $\mathrm{T}$ & 0.413 & 0.416 & $0.414^{b}$ & \\
\hline Mean & 0.404 & 0.411 & 0.407 & \\
\hline \multicolumn{5}{|c|}{ Cortical wall thickness, $\mathrm{mm}$} \\
\hline $\mathrm{F}$ & 2.87 & 2.53 & $2.70^{a}$ & \multirow[t]{3}{*}{0.059} \\
\hline $\mathrm{T}$ & 3.09 & 2.62 & $2.85^{b}$ & \\
\hline Mean & $2.98^{\mathrm{B}}$ & $2.57^{\mathrm{A}}$ & 2.78 & \\
\hline \multicolumn{5}{|c|}{ Cross sectional area, $\mathrm{mm}^{2}$} \\
\hline $\mathrm{F}$ & 99.6 & 97.5 & $98.6^{\mathrm{A}}$ & \\
\hline $\mathrm{T}$ & 120.5 & 105.7 & $113.1^{\mathrm{B}}$ & \\
\hline Mean & $110.1^{\mathrm{B}}$ & $101.6^{A}$ & 105.8 & \\
\hline \multicolumn{5}{|c|}{ Cortical index } \\
\hline $\mathrm{F}$ & 0.78 & 0.66 & 0.72 & \multirow[t]{3}{*}{0.012} \\
\hline $\mathrm{T}$ & 0.76 & 0.65 & 0.70 & \\
\hline Mean & $0.77^{\mathrm{B}}$ & $0.66^{\mathrm{A}}$ & 0.71 & \\
\hline \multicolumn{5}{|c|}{ Maximum strength, $\mathrm{N}$} \\
\hline $\mathrm{F}$ & 964 & 899 & 931 & \multirow[t]{3}{*}{27.71} \\
\hline $\mathrm{T}$ & 894 & 920 & 907 & \\
\hline Mean & 929 & 909 & 919 & \\
\hline
\end{tabular}

${ }^{1} \mathrm{~F}$, T - see Table 2; ${ }^{\mathrm{ab}}$ and ${ }^{\mathrm{AB}}$ - means with different superscripts within a row (bone types comparison) or column (groups comparison) are significantly different at $P<0.05$ and $P<0.01$, respectively
Table 4. Correlation coefficient $(r)$ between fat : lean mass ratio in the body vs bone characteristics based on the results obtained from all animals at the end of the study ( 115 day of life)

\begin{tabular}{lc}
\hline Indices & $\begin{array}{c}\text { Correlation coefficient, } \\
\mathrm{r}(P \text {-value })\end{array}$ \\
\hline Bone weight & $-0.55(P=0.001)$ \\
Bone mineral content & $-0.52(P=0.001)$ \\
Bone mineral density & $-0.27(P=0.029)$ \\
Cortical wall thickness & $-0.37(P=0.002)$ \\
Cross sectional area & $-0.57(P=0.001)$ \\
Cortical index & $-0.08(P=0.553)$ \\
Maximum bone strength & $0.05(P=0.666)$ \\
\hline
\end{tabular}

The 3MT bone was heavier $(P<0.01)$ than 3MC one and had more $(P<0.01)$ bone mineral content, however thinner $(P<0.05)$ cortical wall thickness, lower cross sectional area and cortical index. Bone mineral density and bone maximum strength did not differ between $3 \mathrm{MT}$ and $3 \mathrm{MC}$ bones.

The negative correlations (Table 4) between ratio of fat : lean mass in the body at final age and bone weight $(\mathrm{r}=-0.55, P=0.001)$, bone mineral content $(\mathrm{r}=-0.52, P=0.001)$, bone mineral density ( $\mathrm{r}=-0.27, P=0.029)$, cortical wall thickness $(\mathrm{r}=-0.38, P=0.002)$, cross sectional area $(\mathrm{r}=-0.57$, $P<0.001)$ were detected. The relationship between body fat content and maximum bone strange and cortical index was insignificant.

\section{Discussion}

During the experiment animals were fed the same diet ad libitum, thus, the effect of dietary factors on the studied traits was the same in both groups. It was found that the $\mathrm{T}$ animals consumed less feed in comparison to F pigs. However, despite of $15 \%$ lower feed intake, the $\mathrm{T}$ pigs were even slightly heavier at the end of the study. It was a result of almost $18 \%$ better feed utilization and consequently faster growth rate of this group of animals.

The findings of the present study concerning bone mineral density of the metatarsal and metacarpal bones are different from those presented by Mitchell et al. (2001), Ryan et al. (2011b) and Weremko et al. (2013). According to these authors, bones of the front legs were characterized by higher mineral content because they are subjected to higher biomechanical loads than those of the hind legs regardless of age and dietary factors used in the study. Present results did not confirm such relation as bone of the metacarpal had lower mineral content and similar mineral density in comparison to metatarsal bone. Admittedly cortical wall thickness, cross 
sectional area and cortical index of the metacarpal bone were greater but did not increase the bone strength.

In the present study it was found that bone weight, bone mineral content and density were greater in thin ( $\mathrm{T}$ ) pigs characterized by lower body fatness (fat : lean mass ratio in the body). However, the results of other studies, conducted on human subjects examining a relation between fat content in the body and bone status are conflicting. For instance, Leonard et al. (2004) reported that body fat content positively influences bone mineral content and bone area in the children and adolescents. Similarly, Clark et al. (2006) concluded that fat mass is a positive independent determinant of bone mass and size, which suggests that adipose tissue stimulates bone growth, however this relationship is attenuated by puberty. In contrast, results of numerous studies on overweight and obese children showed that there is a mismatch between body weight and bone development during growth and that bone mass and bone area are too low for their weight (Goulding et al., 2000; Weiler et al., 2000). Similarly, Hsu et al. (2006) showed an inverse relationship between fat mass and bone density. Cole et al. (2012) suggested that fat mass is negatively associated with volumetric bone density in children (independently from lean mass) despite of positive associations with bone size. Similarly, Bredella et al. (2011) demonstrated that adipose tissue was inversely associated with bone mineral density, in contrast to muscle content in the organism that positively influenced this bone parameter.

Presented results showed that in fatter pigs (group F) characterized by higher fat : lean mass ratio in the body worse indices of the bone geometry were measured as their cortical wall thickness and cross sectional area were lower than in pigs characterized by lower value of fat : lean ratio (group T). However, bone strength did not differ between both examined groups. Janicka et al. (2007) using computed tomography found that total body fat mass was not associated with cross sectional area and cortical bone area at the lumbar spine and femoral midshaft of young adults. Contrary Pollock et al. (2007) using peripheral Quantitative Computed Tomography (pQCT) found that young adult obese females had significantly lower cortical bone area, cross sectional area and strength-strain index of tibia as compared to females with physiological body fat level. Lorentzon et al. (2006) suggested that increased total body fat mass may enhance weight-bearing bone geometry.
Determination of the relationship between body composition (fat and lean body mass content) vs bone size/weight, bone mineral content and density is easy for calculation using, e.g., DXA or quantitative computed tomography (QCT) method. However, investigation of such a relationship with regard to the real bone strength in humans is not feasible for obvious reasons. Presented research allowed to determine relationship between body fatness understood as body fat : lean mass ratio vs cortical wall thickness, cross sectional area and bone maximum strength. Our findings were obtained on the basis on the data from all animals used in the study, at the final age. We found that body fatness was inversely correlated with cortical wall thickness and cross sectional area of the metacarpal and metatarsal bones. However, relation with maximum bone strength was insignificant. Earlier, Farr et al. (2010) using QCT method reported that in addition to the lower bone mineral density obese adolescents had markedly reduced geometry and calculated indices of bone strength, which could help to explain why obese adolescents suffer from more fractures than normal weight ones. On the other hand, basing on computer tomography (CT) method results Wetzsteon et al. (2008) reported that bone strength is greater in obese children when absolute value is considered. These authors, however, also pointed that bone strength is appropriately adapted to increased muscle but not to fat mass. This indicates a greater connection between muscle mass and the bone strength. Results of the recent study by Aguirre et al. (2014) pointed out that generally heavier individuals had indeed higher bone mineral density, however in obese individuals, as determined not only by weight but also by fat : lean mass ratio in the body, relatively lower bone mineral density was stated. In obese individuals high percentage of fat mass and low percentage of lean mass correlated with decreased bone mineral density and increased frailty due to lower bone strength. Moreover, Mosca et al. (2014) reported negative relationship between body fat, and whole body bone mineral content and density in males, and between body fat and bone mineral density of femur and spine in females. Authors concluded that excess of fat mass is detrimental to the development of bone mass in male adolescents, whereas in females the femur and spine bone mineral density are the most affected ones. Viljakainen et al. (2011) found a negative correlation between body fatness and bone strength, bone fracture load, bone turnover and whole body bone mineral density 
in children and adolescents. Authors concluded that body fat content on physiological level supports bone health, but a high one has an inverse effect.

Despite of the direct relation between body fatness, and bone mineralization, geometry and mechanical properties shown in the present study, a review of the literature clearly pointed out a physiologically predominant role of the adipose tissue in the body energy balance by synthesizing an array factors that regulate satiety (leptin), insulin sensitivity (adiponectin and resistin), hormones (oestrone) as well as proinflammatory molecules (Rajala and Scherer, 2003; Sun at al., 2011). Moreover, all of these factors can directly or indirectly influence bone turnover, skeletal growth and bone properties demonstrating the dynamic nature of the skeleton relative to adipocyte tissue. Understanding the mechanisms and the effects of these factors on the mineralization, geometry and mechanical properties of bone in individuals with varying body energetic status, understood as ratio of fat : lean mass in the body, requires further research including animal studies.

\section{Conclusions}

Body fatness understood as fat : lean mass ratio is inversely correlated with bone size/weight, degree of bone mineralization (bone mineral content, bone mineral density) and bone geometry (cortical wall thickness and cross sectional area) and is in contrast to bone mechanical properties (bone strength).

\section{Acknowledgements}

This experiment was supported by statutory funds of the Kielanowski Institute of Animal Physiology and Nutrition, Polish Academy of Sciences (Jabłonna, Poland).

\section{References}

Aguirre L., Napoli N., Waters D., Qualls C., Villareal D.T., ArmamentoVillareal R., 2014. Increasing adiposity is associated with higher adipokine levels and lower bone mineral density in obese older adults. J. Clin. Endocrinol. Metab. 99, 3290-3297, https://doi.org/10.1210/jc.2013-3200

Beyer M., Jentsch W., Chudy A., 2003. Rostock Feed Evaluation System: Reference Numbers of Feed Value and Requirement on the Base of Net Energy. Plexus-Verlag. Miltenberg (Germany)

Bredella M.A., Torriani M., Ghomi R.H., Thomas B.J., Brick D.J., Gerweck A.V., Harrington L.M., Breggia A., Rosen C.J., Miller K.K., 2011. Determinants of bone mineral density in obese premenopausal women. Bone 48, 748-754, https://doi. org/10.1016/j.bone.2010.12.011
Clark E.M., Ness A.R., Tobias J.H., and the Avon Longitudinal Study of Parents and Children Study Team, 2006. Adipose tissue stimulates bone growth in prepubertal children. J. Clin. Endocrinol. Metab. 91, 2534-2541, https://doi.org/10.1210/ jc.2006-0332

Cole Z.A., Harvey N.C., Kim M., Ntani G., Robinson S.M., Inskip H.M., Godfrey K.M., Cooper C., Dennison E.M., 2012. Increased fat mass is associated with increased bone size but reduced volumetric density in pre pubertal children. Bone 50, 562-567, https://doi.org/10.1016/j.bone.2011.05.005

Crenshaw T.D., Peo E.R. Jr., Lewis A.J., Moser B.D., Olson D., 1981. Influence of age, sex and calcium and phosphorus levels on the mechanical properties of various bones in swine. J. Anim. Sci. 52, 1319-1329, https://doi.org/10.2527/ jas1981.5261319x

Dytfeld J., Ignaszak-Szczepaniak M., Gowin E., Michalak M., HorstSikorska W., 2011. Influence of lean and fat mass on bone mineral density (BMD) in postmenopausal women with osteoporosis. Arch. Gerontol. Geriatr. 53, e237-e242, https://doi. org/10.1016/j.archger.2011.01.002

Farr J.N., Chen Z., Lisse J.R., Lohman T.G., Going S.B., 2010. Relationship of total body fat mass to weight-bearing bone volumetric density, geometry, and strength in young girls. Bone 46, 977-984, https://doi.org/10.1016/j.bone.2009.12.033

Goulding A., Taylor R.W., Jones I.E., McAuley K.A., Manning P.J., Williams S.M., 2000. Overweight and obese children have low bone mass and area for their weight. Int. J. Obesity 24 , 627-632, https://doi.org/10.1038/sj.ijo.0801207

Hsu Y.-H., Venners S.A., Terwedow H.A. et al., 2006. Relation of body composition, fat mass, and serum lipids to osteoporotic fractures and bone mineral density in Chinese men and women. Am. J. Clin. Nutr. 83, 146-154

Janicka A., Wren T.A.L., Sanchez M.M., Dorey F., Kim P.S., Mittelman S.D., Gilsanz V., 2007. Fat mass is not beneficial to bone in adolescents and young adults. J. Clin. Endocrinol. Metab. 92, 143-147, https://doi.org/10.1210/jc.2006-0794

Kirchengast S., Peterson B., Hauser G., Knogler W., 2001. Body composition characteristics are associated with the bone density of the proximal femur end in middle- and oldaged women and men. Maturitas 39, 133-145, https://doi. org/10.1016/S0378-5122(01)00205-5

Leonard M.B., Shults J., Wilson B.A., Tershakovec A.M., Zemel B.S., 2004. Obesity during childhood and adolescence augments bone mass and bone dimensions. Am. J. Clin. Nutr. 80, 514-523

Lorentzon M., Landin K., Mellström D., Ohlsson C., 2006. Leptin is a negative independent predictor of areal BMD and cortical bone size in young adult Swedish men. J. Bone Miner. Res. 21, 1871-1878, https://doi.org/10.1359/jbmr.060814

Mitchell A.D., Scholz A.M., Pursel V.G., 2001. Total body and regional measurements of bone mineral content and bone mineral density in pigs by dual energy X-ray absorptiometry. J. Anim. Sci. 79, 2594-2604, https://doi.org/10.2527/2001.79102594x

Mosca L.N., Goldberg T.B.L., da Silva V.N., da Silva C.C., Kurokawa C.S., Rizzo A.C.B., Corrente J.E., 2014. Excess body fat negatively affects bone mass in adolescents. Nutrition 30 , 847-852, https://doi.org/10.1016/j.nut.2013.12.003

Pollock N.K., Laing E.M., Baile C.A., Hamrick M.W., Hall D.B., Lewis R.D., 2007. Is adiposity advantageous for bone strength? A peripheral quantitative computed tomography study in late adolescent females. Am. J. Clin. Nutr. 86, 1530-1538

Rademacher M., Sauer W.C., Jansman A.J.M., 2001. Standardized lleal Digestibility of Amino Acids in Pigs. Degussa-Hüls AG publication, Frankfurt am Main (Germany) 
Rajala M.W., Scherer P.E., 2003. Minireview: The adipocyte - at the crossroads of energy homeostasis, inflammation, and atherosclerosis. Endocrinology 144, 3765-3773, https://doi. org/10.1210/en.2003-0580

Reid I.R., Plank L.D., Evans M.C., 1992. Fat mass is an important determinant of whole body bone density in premenopausal women but not in men. J. Clin. Endocrinol. Metab. 75, 779-782, https:// doi.org/10.1210/jcem.75.3.1517366

Rothney M.P., Brychta R.J., Schaefer E.V., Chen K.Y., Skarulis M.C., 2009. Body composition measured by dual-energy X-ray absorptiometry half-body scans in obese adults. Obesity 17 , 1281-1286, https://doi.org/10.1038/oby.2009.14

Ryan W.F., Lynch P.B., O'Doherty J.V., 2011a. Compensatory effect of dietary phosphorus on performance of growing pigs and development of bone mineral density assessed using dual energy X-ray absorptiometry. Livest. Sci. 138, 89-95, https:// doi.org/10.1016/j.livsci.2010.12.006

Ryan W.F., Lynch P.B., O'Doherty J.V., 2011b. Effect of dietary phosphorus on the development of bone mineral density of pigs assessed using dual energy X-ray absorptiometry. Livest. Sci. 137, 101-107, https://doi.org/10.1016/j.livsci.2010.10.006

Shaw D.T., Rozeboom D.W., Hill G.M., Orth M.W., Rosenstein D.S., Link J.E., 2006. Impact of supplement withdrawal and wheat middling inclusion on bone metabolism, bone strength, and the incidence of bone fractures occurring at slaughter in pigs. J. Anim. Sci. 84, 1138-1146, https://doi.org/10.2527 2006.8451138x

Skiba G., Weremko D., Sobol M., Raj S., 2015. Bone mineralisation of weaned piglets fed a diet free of inorganic phosphorus and supplemented with phytase, as assessed by dual-energy Xray absorptiometry. Arch. Anim. Nutr. 69, 267-275, https://doi. org/10.1080/1745039X.2015.1054163
Sun K., Kusminski C.M., Scherer P.E., 2011. Adipose tissue remodeling and obesity. J. Clin. Invest. 121, 2094-2101, https://doi. org/10.1172/JCl45887

Varley P.F., Callan J.J., O'Dohert J.V., 2011a. Effect of dietary phosphorus and calcium level and phytase addition on performance, bone parameters, apparent nutrient digestibility, mineral and nitrogen utilization of weaner pigs and the subsequent effect on finisher pig bone parameters. Anim. Feed Sci. Technol. 165, 201-209, https://doi.org/10.1016/j.anifeedsci.2011.02.017

Varley P.F., Sweeney T., Ryan M.T., O'Doherty J.V., 2011b. The effect of phosphorus restriction during the weaner-grower phase on compensatory growth, serum osteocalcin and bone mineralization in gilts. Livest. Sci. 135, 282-288, https://doi. org/10.1016/j.livsci.2010.07.025

Viljakainen H.T., Pekkinen M., Saarnio E., Karp H., Lamberg-Allardt C., Mäkitie O., 2011. Dual effect of adipose tissue on bone health during growth. Bone 48, 212-217, https://doi.org/10.1016/j. bone.2010.09.022

Weiler H.A., Janzen L., Green K., Grabowski J., Seshia M.M., Yuen K.C., 2000. Percent body fat and bone mass in healthy Canadian females 10 to 19 years of age. Bone 27, 203-207, https://doi. org/10.1016/S8756-3282(00)00314-8

Weremko D., Skiba G., Raj St., Fandrejewski H., 2013. The effects of feed and protein restriction between 90 and 118 days of age on performance, bone growth and mineralization of pigs reared to 168 days of age. Anim. Feed Sci. Technol. 182, 53-60, https://doi.org/10.1016/j.anifeedsci.2013.04.004

Wetzsteon R.J., Petit M.A., Macdonald H.M., Hughes J.M., Beck T.J., McKay H.A., 2008. Bone structure and volumetric BMD in overweight children: a longitudinal study. J. Bone Miner. Res. 23, 1946-1953, https://doi.org/10.1359/jbmr.080810 